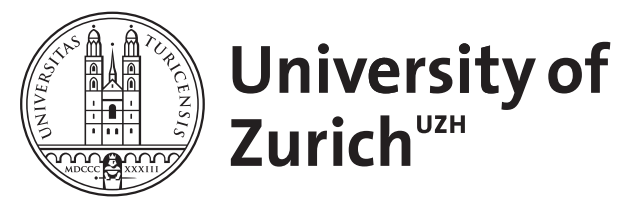

\title{
Molecular diagnostics in endodontics
}

\author{
Rechenberg, Dan-Krister ; Zehnder, Matthias
}

\begin{abstract}
Recent systematic reviews have substantiated the fact that current testing methods to assess the inflammatory state of the pulp and the periapical tissues are of limited value. Consequently, it may be time to search for alternative routes in endodontic diagnostics. Molecular assessment methods could be the future. However, in the field of endodontics, the research in that direction is only about to evolve. Because pulpal and periradicular diseases are related to opportunistic infections, diagnostics can either target microorganisms or the host reaction. This communication discusses clinical situations in which a molecular assessment of infection or host reaction could be of interest. The methods, collection sites, current state of research, and unresolved problems are evaluated.
\end{abstract}

DOI: https://doi.org/10.1111/etp.12057

Posted at the Zurich Open Repository and Archive, University of Zurich

ZORA URL: https://doi.org/10.5167/uzh-99781

Journal Article

Accepted Version

Originally published at:

Rechenberg, Dan-Krister; Zehnder, Matthias (2014). Molecular diagnostics in endodontics. Endodontic Topics, 30(1):51-65.

DOI: https://doi.org/10.1111/etp.12057 


\section{Molecular diagnostics in endodontics}

\section{Dan-K. Rechenberg \& Matthias Zehnder*}

Department of Preventive Dentistry, Periodontology and Cariology, University of Zürich, Center of Dental Medicine, Zürich, Switzerland

*Corresponding author: Prof. Dr. Matthias Zehnder, PhD

University of Zürich Center for Dental Medicine

Department of Preventive Dentistry, Periodontology and Cariology

Plattenstrasse 11

CH-8032 Zürich, Switzerland

Tel: +41446343438

Fax: +41446344308

E-mail: matthias.zehnder@zzm.uzh.ch 


\begin{abstract}
:
Rechenberg DK, Zehnder M. Molecular diagnostics in endodontics. Endod Topics

Recent systematic reviews have substantiated the fact that current testing methods to assess the inflammatory state of the pulp and the periapical tissues are of limited value. Consequently, it may be time to search for alternative routes in endodontic diagnostics. Molecular assessment methods could be the future. However, in the field of endodontics the research in that direction is only about to evolve. Because pulpal and periradicular disease are related to opportunistic infections, diagnostics can either target microorganisms or the host reaction. This communication discusses clinical situations, in which molecular assessment of infection or host reaction could be of interest. Methods, collection sites, current state of research and unresolved problems are evaluated.
\end{abstract}




\section{Introduction}

The term "diagnosis" stems from the ancient Greek concept of relating a disease to a tangible cause rather than to the will of a higher power. Translated to English, diagnosis, from $\delta 1 \alpha$ and $\gamma \nu \omega ́ \sigma \eta$, means "thorough understanding", i.e. to understand the cause-effect relationship in a specific disease. In clinical endodontics, the cause of disease is opportunistic infection of dental hard tissues by oral or transient microorganisms $(1,2)$. If these infections are removed, the dental

pulp and periapical tissues have a high propensity to heal $(3,4)$. Consequently, endodontic diagnostics should focus on either the extent of the microbial infection, or the inflammatory reaction of the host tissue. Strangely enough, current methods do neither $(5,6)$. Instead, pulp tests are based on triggering a nerve response, while periapical diagnostics rely on radiographic imaging. These methods have their clear benefits in everyday clinical practice, but also their limitations, which have been discussed elsewhere (5-7), and shall not be detailed in the current communication. Methods concentrating on pulpal blood flow are also beyond the scope of this communication and not discussed. Laser Doppler flowmetry (8), pulp oxyometry (9), and dualwavelength spectrophotometry (10) can be useful in coronally intact front teeth after trauma (6). However, the application of those methods is limited by their inability to monitor teeth with restorations and lateral teeth. Therefore it is unlikely that they will gain much relevance in restorative dentistry and endodontics.

The great majority of papers on pulp diagnosis has focused on the question: is the pulp histologically/clinically vital or necrotic? Based on this dichotomized outcome, sensitivity and specificity of a test can be calculated. In clinical practice, however, other questions are asked, such as: "Will the pulp survive after I placed a permanent restoration?" or "Is the periapical inflammation about to recede after root canal treatment has been initiated?". These questions are not addressed at all with current diagnostic tools. 
This paper will focus on the possibility to diagnose pulpal and periapical inflammation via molecular markers. As is discussed in the following text, this approach could reveal information from a spatially restricted area, which may help to save vital tissues.

\section{A brief take on the status quo of endodontic diagnostics}

\section{Monitoring pulpal health}

The history of a tooth can have a great impact on treatment decision. However, in the context of correct diagnosis of the state of the pulp, anamnestic information can only contribute to, but not tell, the overall picture. It has been shown that whether or not a tooth has a history of pain does not necessarily reveal much about its condition $(11,12)$. Monitoring pulpal health is therefore recommend during routine dental check-ups and after operative procedures aiming at maintaining pulpal vitality. The most common method is the cold test, using either a carbon dioxide pencil or a cotton pellet saturated with refrigerant spray (1,1,1,2-tetrafluoroethane). The application of cold to tooth crowns stimulates vital, thermo-sensitive nerve fibers. In case of a sensitive pulp the patient perceives a tickling or painful sensation. Further methods are the application of heat, electric currents (electric pulp test), or even test drilling through present restorations. However, the validity of such tests is frequently limited in teeth with coronal restorations, with pulp canal obliteration, or after trauma. The advantages and disadvantages of the respective methods are discussed in detail elsewhere $(5-7,13)$. Nevertheless, it is worth mentioning in that context that all the common pulp tests solely rely on the patient's subjective response to a stimulus. Depending on several factors like anxiety, cultural background or the patient's mood, this stimulus can be perceived differently. Because current pulp tests are not able to identify the state of the pulp, they should be called "sensitivity tests" rather than "vitality tests". 


\section{Monitoring periapical health}

Teeth with a negative sensitivity test are checked radiographically to identify the presence or absence of apical periodontitis. The presence of a periapical radiolucency is correlated with pulpal necrosis and histologic signs for inflammation at the periapex (14). However, intact tissues including nerve fibers have been observed histologically in the pulp stump of the apical root third, despite the presence of an apparent periapical lesion (15). Moreover, on single radiographs, it can take up to one year to see a decisive change in the appearance of the periapex (16). A further problem with two-dimensional imaging is anatomical blurring. (17, 18). Apical periodontitis in cancellous bone, for example, can be non-detectable radiographically, even though extensive disease is present $(17,18)$. In theory, three-dimensional imaging may overcome this problem (19). However, radiation to oral tissues with current methods is still not acceptable for standard monitoring (20). Furthermore, while such data exist for conventional radiographs $(14,21)$, the correlation between the histology of periapical tissues and their radiographic appearance has not been established in three-dimensional images. As an example, it is not know what scar healing would look like on cone-beam images (22). Moreover, as shown most recently, healthy teeth can have a widened ligament in cone-beam images (23).

\section{Pulpal and periapical inflammation}

In the context of diagnostics, it would appear to be of utmost importance to understand the inflammatory diseases we treat or try to prevent in everyday clinical practice. Our focus should especially be on the location of the inflammation at a given condition (Fig. 1).

Pulpal inflammation, in the vast majority of cases, is triggered by micro-organisms. These enter the pulp space either through caries (15), traumatic fractures or cracks in the dentin (24), or, in the absence of a functioning pulp, exposed dentinal tubules (25). The oral microbiota interacts 
with the hard tissues of the tooth crown. This is also why the infectious process initiates in the crown or the cervical area of the tooth. As the infection progresses from the coronal to the apical aspects of the root canal system, a radiographic lesion around the portals of exit of the root canal system becomes apparent. The radiographic lesion reflects the advancing periapical bone resorption, which is part of the host response to the presence of micro-organisms in the root canal (26). As the disease process continues, biofilm formation occurs all the way into the complex anatomy of the root apex (27), which can be extremely difficult to debride and disinfect $(28,29)$. This may be seen as the biological reason why the presence or absence of a periapical lesion prior to intervention is the main predictor for the radiological outcome of root canal treatment $(30,31)$. From the aspect of preventive dentistry, it should be clear that hindering the progression of pulpal infection should be the aim. Conceptually, as Paracelsus knew 500 years ago: "If you prevent infection, Nature will heal the wound by herself" (32). At the same time, vital, non-infected tissues should be preserved. Primum non nocere (Scribonius Largus, approximately 50 AD) has remained a core ethical principle in medicine (33). This is currently not done, or at least not consequently practiced in everyday clinics. As will be discussed below, the lack of proper diagnostic methods plays a major role in this context. Or in other words: as long as we do not know what we treat, overtreatment seems to be easier and more predictable than preservation of vital tissues. As an example, if we attempt to maintain vitality in a pulp, which is, in reality, irreversibly inflamed, the patient may experience excruciating pain in the future (Fig. 1, top right). In a retrospective study on the survival of pulps after direct pulp capping procedures in teeth with a normal response to the cold test, a mere $20 \%$ of the pulps remained vital after 10 years (34). This also suggests that at least $50 \%$ of the teeth that lost pulpal vitality during the observation period should have caused some form of memorable discomfort to the patient (12). 


\section{Treatment concepts: from the crown to the apex and back again}

\section{Maintaining coronal pulp vitality}

Infection of the dentin-pulp continuum usually initiates in the coronal aspect of the tooth and progresses apically. The main reason is caries, which will be discussed in some detail. However, cracks in the dentin should not be left unmentioned, as they can be the hidden cause of irreversible pulpitis and its typical clinical symptoms (35). Regardless of the route of microbial challenge to the pulp, it is not quite clear when an actual intervention into the pulp is necessary and when it is not. In caries that does not reach into the inner $1 / 3$ of the dentin, complete excavation is not mandatory. A tight coronal seal is apparently sufficient to arrest the process (36). The same may be true for caries that reaches into the inner $1 / 3$ on the preoperative radiograph. At least in the short-term, step-wise excavation has consistently performed better than full excavation in terms of maintaining pulp vitality (37-39). However, patients experiencing spontaneous pain prior to treatment were excluded in these studies. If pain is taken as an outcome, there was no difference between stepwise excavation and direct pulp capping. In the most detailed and scientifically sound randomized trial on the topic of complete versus partial excavation to date (39), 8 of 143 patients in the stepwise excavation group experienced unbearable pain leading to pulpectomy within the first year after treatment, compared to 7 of 149 patients in the complete excavation group $(P=0.93)$. Long-term follow-up studies exist only for direct pulp capping. These show a consistent yearly failure rate, culminating in maintained pulpal vitality as low as $20 \%$ after 10 years (34).

Another, often overlooked, reason for loosing pulpal vitality is devitalization through preparation of teeth for indirect fixed reconstructions. Systematic reviews have suggested that roughly $10 \%$ of abutment teeth pulps become necrotic within 10 years after restoration (40). However, the true number may be higher, as these reviews included studies that did not specifically focus on the 
assessment of pulp vitality. Cheung and co-workers followed 199 initially vital abutment teeth for a mean of 15 years (41). Of these teeth, 77 were bridge abutments, while 122 were restored with single metal-ceramic crowns. Of the bridge abutments, $32.5 \%$ became necrotic during the observation period, compared to $15.6 \%$ of the crowned teeth $(P<0.93)$. This is in line with the classic study on teeth with advanced periodontal disease that were included in long-span bridges (42). Of the abutment teeth, $15 \%$ developed pulpal necrosis over 9 years, compared to $3 \%$ of the teeth, which were not included in the reconstructions.

\section{Pulpotomy versus pulpectomy}

In current clinical practice, the treatment of teeth with necrotic, partly vital, and vital pulps is the same: full pulpectomy. The designated treatment goal of pulpectomy is the removal of all organic substrate from the root canal system (43). This, however, is not based on any biological or clinical facts (44), but rather on radiological esthetics. Earlier authors realized that dentin chips obtained from instrumenting non-infected root canals are the perfect biomaterial to seal off root canals $(45,46)$. The preparation goal in many schools was to instrument $3 \mathrm{~mm}$ short in vital cases, to maintain a vital pulp stump in the apical root canal system (47). This concept, however, has not stood the test of time. The reason for instrumenting to full working length is probably two-fold: the endodontist can show his or her skills on the radiograph, which can then be appreciated at recall also by another dentist, who may not know whether a tooth contained a vital pulp prior to treatment or had apical periodontitis. The second reason is that during endodontic treatment it is currently not possible to know whether the remaining tissue is free of bacterial infection or not. Conversely, it may be so that in most vital teeth with irreversible pulpitis, it is unnecessary to instrument and fill the root at all. Complete pulpotomy, i.e. the removal of the coronal pulp without entering the root canals, in combination with a tight coronal seal, could 
become a valid treatment in cases of irreversible pulpits (48). Some randomized trials have pointed in that direction $(49,50)$. Unfortuantely, the authors of these articles were found guilty of submitting data to different journals simultaneously. Their articles on pulpotomy versus pulpectomy were removed from the Journal of Dental Research and the Journal of Endodontics. Consequently, we have to wait for results from other groups to validate these potentially important data.

\section{Pulp tissue engineering}

Tissue regeneration strategies have gained substantial attention in the dental literature over the recent years (51). Among the regenerative dental procedures, revascularization of a necrotic pulp space appears to be the treatment option that holds the most promise for the immediate future (52). The idea to revascularize a necrotic pulp space to induce continuing root formation is not new. In fact, it is a common procedure in dental traumatology (53). The first report to describe this procedure in teeth affected by caries and its sequelae dates back half a century (54). However, a subsequent study in vital and non-vital human teeth of adult patients showed that revascularization was only possible in teeth that had contained a vital pulp prior to treatment (55). The tooth revascularization concept disappeared for three decades, only to resurge some years ago in the form of case reports (56). The so-called revascularization procedure is deemed to be especially helpful in children with teeth with incomplete root formation. In a first visit, the root canal system is disinfected by irrigation with a sodium hypochlorite solution and the placement of an antibiotic paste. In a following visit, the paste has to be removed, and after inducing bleeding from the apical tissues, the blood clot in the coronal aspect of the root canal is sealed off using a calcium-silicate cement covered by a permanent restorative material (57). Ideally this procedure results in continuing root development in length and width. Recent observations, 
however, question whether new dentin formation really occurs. What probably happens is that, once the infection is treated, periodontal tissues grow into the pulp space of the immature root with the open apex (58). A track that has not been followed, but would be worth doing so, is the idea to grow back pulps in cases with some vital pulp aspects. Recent advances in tissue engineering and cell homing could make it possible to extend this concept to adult teeth, which contain some vital pulp tissue (59).

\section{Why could molecular diagnostics be helpful?}

The patient's subjective response to traditional pulp sensitivity tests should be overcome. Furthermore, diagnostic methods should be more site-specific and accurate than the tests we currently have. This would enable to avoid overtreatment and to maintain vital tissues. Such methods could help to delineate the spatial level of surgical intervention, i.e. debridement, necessary in a given clinical situation. In restorative dentistry, this could help to determine whether a pulp needs any kind of treatment prior to restoration or not. This would be helpful for direct or indirect pulp capping procedures as well as for the assessment of the general pulpal health before replacement of fillings or indirect restorations. In terms of the root canal treatment itself, it would be good to know whether a pulp can be kept in its entirety, or, if pulpotomy or amputation of the pulp is intended, at which level this procedure should be executed. Furthermore, if pulpectomy is performed in teeth with apical periodontitis, it should be helpful to know whether the inflammation in the periapex is about to heal prior to obturation of the root canal system.

For all the above tasks, molecular analysis of the site of invention could be of diagnostic value. As we deal with opportunistic infections, the first question that arises in this context is whether 
molecules that reflect bacterial presence or counterparts that indicate the inflammatory state of the involved tissues would be preferable to identify and/or analyze.

\section{Bacteria or host response?}

Targeting bacteria allows direct assessment of the cause of disease. Historically, the root canal content was cultured either to confirm the reduction or absence of bacteria prior to obturation, or to define the individual bacterial composition of the infection. The latter was done to generate an antibiogram, on which the clinician was supposed to choose the suitable antibiotic for the therapy (60). However, endodontic infections have been shown to be non-specific and composed of mixed microorganisms (61). They are driven by ecological factors rather than specificities of the invading species, and thus the concept of the "ecological plaque hypothesis" (62) should not only be extended to periodontal but also to endodontic infections (63). Taken together, those circumstances make it rather unlikely that is might be possible to identify an individual key microorganism, or even a specific group-set of microorganisms, of superior diagnostic value. The elusiveness of site-specific micro-organisms, which are routinely present at the forefront of endodontic infections, but absent from other oral sites, renders root canal sampling for diagnostic purposes error-prone. Culture methods, once mandatory for dental students, have been questioned and abandoned for routine root canal treatments (44). In addition, there are methodological pitfalls associated with culturing microorganisms from root canals (64). Contamination is always a problem. Meticulous precautions have to be applied to avoid false positive results when microbial samples are collected from root canals for research purposes $(65,66)$.

As a more straight-forward alternative to culturing, it may be possible to identify sessile bacterial aggregates directly by simple optical methods (Fig.2). It has been shown that bacterial colonies can be excited with filtered xenon light $(405 \pm 20 \mathrm{~nm})$ and viewed through a 530 -nm high-pass 
filter (67). This approach is used in cariology for conservative caries excavation (68). There is now a commercially available system on the market called FACE (fluorescence-aided caries excavation, Sirona, Bensheim, Germany). Effectively, FACE does not trace bacteria, but porphyrine compounds in dentin associated with microbial presence (69). Theoretically, this method could be helpful to be used in vital pulp therapy. After a pulpotomy procedure, it could be used to assess whether the remaining tissue or the root canal dentin is infected or not. However, it is currently not known whether fluorescence methods are suitable to track pulpal infection. Studies should be performed to figure this out.

In the context of molecular diagnostics, there are some clear advantages to assess the host response rather than bacterial invasion. That is probably why there have been more approaches in that direction. Each site and tissue fluid has its specific environment of host factors (70-72). This fact, per se, can circumvent the problem of contamination with e.g saliva. The composition of the respective analyte can be altered because of the proximity to an inflammatory process. Therefore factors associated with disease can be associated or controlled against counterparts associated with health.

\section{Which fluid to collect?}

Depending on the different clinical situations given, intervention may aim in maintaining pulpal vitality or regaining periapical health. Logic would dictate that different clinical situations have to be approached with different tests. Biologically, the main target should be to locate the bacterial invasion in the continuum of the pulp space and the periapex (Fig. 1). The following text will discuss sampling fluids and sites.

\section{Gingival crevicular fluid (GCF)}


GCF is an exudate that derives from the gingival crevice. It contains a multitude of host factors including antibodies, bacterial antigens, proteins and cytokines (73). In the late 1950s the idea was born to correlate molecular markers of GCF with periodontal inflammation, because GCF is produced and modified by the periodontal ligament (74). Since then many studies showed that host factors are differentially present in the GCF of periodontally affected teeth compared to healthy counterparts (75). The same has been shown for orthodontically induced root resorption (76) and trauma induced root resorption (77). All those observations share the feature that periodontal inflammation is assessed, regardless of the underlying cause. This is possible because the neural and vascular supplies of the periodontium and endodontium are functionally and anatomically connected $(78,79)$. Since collecting GCF is a non-invasive procedure, it might thus provide diagnostic information for any given clinical situation. However, studies investigating changes of host factors in GCF of endontically-involved teeth are relatively sparse. Some studies showed that the composition of neurotransmitters, interleukin- 8 or MMP- 8 differs in GCF of painful and non-painful teeth (80-83). Other investigations pitched at evaluating the differences in molecular composition of GCF between teeth with asymptomatic apical periodontitis compared to non-diseased controls (84-86).

GCF analyses are deemed to be promising by some researchers, because apical periodontitis, like marginal periodontitis, is a local inflammation of the periodontal ligament. And indeed, in theory it might be even possible to assess the dynamics of apical periodontitis (e.g. healing of apical periodontitis after root canal treatment) using GCF. However, one major drawback in the evaluation of host mediators in GCF is that tissue inflammation, independent of its cause, is a non-specific process of the innate immunity (87). This renders it difficult, if not impossible, to distinguish on a molecular level between a marginal and an apical periodontal inflammation. Thus, there will always be bias from gingival or periodontal inflammation in GCF analyses 
targeted at pulpal or periapical disease. Furthermore, the GCF is unlikely to be able to reflect the spatial level of microbial progress in the pulp space, which, as delineated above, should dictate treatment decisions. The gingival crevice is thus probably not the most ideal collection site for molecular diagnostics in endodontics.

\section{Pulpal blood}

Blood and its cellular components play an essential role in the specific and the non-specific immune system. Hemogram analyses are a standard of care in general medical practice and enable to draw conclusions on a variety of conditions with an effect on blood composition. Blood from the pulp can carry factors, which differ from those in the peripheral blood (88), indicating that there is site-specific information to be gained from this fluid.

The first person to investigate a pulpal blood hemogram was Dr. Florian Prader at the University of Zürich (70). In 1949 he compared pulpal blood smears of teeth with advancing endodontic infection to their inflammatory status assessed by histology and concluded, that progressing bacterial involvement is associated with a quantitative elevation of cellular blood compounds, most prominently polymorphonuclear neutrophil granulocytes (PMNs). About fifteen years later, Guthrie and co-workers published their classic study on pulpal blood examination (89). They compared clinical signs and symptoms of endodontically involved teeth with pulpal blood smears and the histologic status of those same teeth after extraction. The authors made two main observations, which are worth to be repeated word by word:

1) "The fact that a high percentage of the pulps in the poor risk (for vital pulp therapy) group bled profusely from the exposed site upon removal of the caries, gave limited support to the belief that excessive hemorrhage from an exposed pulp is one contraindication for vital pulp therapy.“ 
2) "It was interesting to note that non of the teeth which exhibited high neutrophil counts were found to be in the good risk group (histologically)."

This study highlighted again the pivotal role of PMNs in the breakdown of the pulp.

Since the Guthrie study, merely two studies used modern molecular techniques (enzyme-linked immunosorbent assay, ELISA) to evaluate pulpal human blood for molecular markers at the protein level $(90,91)$. Nakanishi and co-workers looked at upstream markers in the inflammatory cascade, and found that $\operatorname{IgG}$, IgA, IgM, elastase, and especially prostaglandin E2, but not IL-1 and IL-6 were elevated in inflamed compared to healthy teeth. A recent study found that the neutrophil-attracting chemokine IL-8 was significantly elevated in symptomatic pulpitis teeth compared to clinically healthy counterparts and teeth with mere caries exposure of the pulp (91). One reason that this field of research did not gain much attention in the past may be that sampling pulpal blood requires entering the pulp space. It has been shown that entering the pulp space lessens the chance of the pulp to survive (39). Nevertheless, current scientific intentions aiming at pulpal revascularization or regeneration have in common that the pulp space is accessed. In such situations molecular diagnostic of pulpal blood might provide valuable information on the condition of the pulp. There may be an impasse though, and that is the fact that blood interferes with most protein assays $(92,93)$.

\section{Dentinal fluid}

Dentinal fluid is the extracellular fluid that is contained in dentinal tubules (94). The idea to sample dentinal fluid from the dentin wound to assess the state of the pulp stems from the research group around Professor Pashley (95). It was suggested to assess factors associated with PMNs, which makes a lot of sense, as was already noted by Guthrie and co-workers (89), and will be discussed later in this text. The Pashley group performed a multitude of studies on the 
fluid flow through dentin in teeth of the dog. The first study on protein levels in dentinal fluid in human teeth collected in situ was performed by Knutsson and co-workers (96). These authors filled access cavities with saline solution, and collected the content of the access cavity 15 min after application to analyze serum albumin levels. This is clinically not practicable and highlights the main problem with dentinal fluid collection: low yields of protein. In in vitro studies this problem may be overcome by collecting the whole fluid content of an extracted tooth by occlusal trimming and centrifugation (97). However, this is not possible in studies on vital teeth, and thus samples have been pooled from multiple teeth (98). This approach, for obvious reasons, cannot be taken in diagnostics.

In a relatively recent study on dentinal fluid analysis in clinically healthy and highly painful teeth affected by clinically irreversible pulpitis, folded polyvinylidene difluoride (PVDF) membranes were used to collect dentinal fluid from exposed dentin. The dentin wound was dried by pressured air prior to collection (99). MMP-9 was identified by a highly sensitive assay in 7 of 16 teeth diagnosed with irreversible pulpitis, compared to zero MMP-9-positive samples from the 12 healthy control teeth. The inconsistent recovery of MMP-9 in the clearly symptomatic pulpitis teeth was related to low yields and the possible inability of the PVDF membrane to absorb the fluid from the tubules. As has been shown in the context of GCF collection and analysis, the type of vehicle that is used has a great impact on protein absorption and release (100). Consequently, the authors performed a study to compare different vehicles for possible dentinal fluid collection in vitro and in vivo (101). It was found that large-pore cellulose membranes yielded more of a molecule of diagnostic value (MMP-2) compared to PVDF counterparts. However, more research is necessary to assess whether or not dentinal fluid analysis could ever become clinically feasible and meaningful. 
It is certainly so that, if procedural problems can be resolved, dentinal fluid diagnostics would be most helpful in all the dental interventions that aim at maintaining a healthy coronal pulp. Dentinal fluid analysis could shine some light on the clinically unresolved questions of whether or not a pulp has a chance to survive indirect pulp capping or the mere preparation of the tooth as an abutment for an indirect restoration.

\section{Periapical fluid}

The term "periapical fluid", or "periapical tissue fluid" refers to the extracellular fluid present in the periapical area. If the periapical tissues become inflamed, the periapical fluid becomes an exudate, and its composition is modified (102). There are different sub-types of exudates. In case of severe inflammation, for example, an exudate can become purulent and contains dead cell fragments (e.g. from PMNs). Because exudate formation is an immediate host reaction, analysis of the exudate may provide useful information about the current state of inflammation. Collecting periapical fluid during root canal treatment is feasible after full pulpectomy. Ascending periapical fluid has been collected either by inserting a paper point or a methylcellulose strip to working length, or by aspiration with a syringe $(72,103,104)$. Studies on apical root anatomy of permanent human teeth showed that the diameter of the apical constriction is usually $\geq$ ISO-size 20 (105). Therefore, it is even possible to protrude a small-sized paper point slightly beyond the apical constriction to collect the tissue fluid present there (106).

One outstanding feature of analyzing periapical fluid is that it enables researchers to study the inflammatory response to a microbial infection in a closed environment in humans (107). The background noise of mediators not induced by the immediate disease process, a common problem with GCF analysis, is not present. Bacteria-related factors like endotoxin, and host-related factors like cytokines, immunoglobulins, or MMPs have been identified from periapical exudates in 
human root canals $(72,108-110)$. The concentrations or ratios of some factors in periapical fluid have been shown to correlate with clinical signs and symptoms (111-113), the presence of purulent exudate $(102,114)$, or the size of the preoperative apical radiolucency $(104,108,115)$. Furthermore, a relation between root canal treatment and the decrease of certain factors could be established $(102-104,110)$. Overall, those studies suggest that periapical fluid can be analyzed for molecular markers and that their concentration can change under different clinical conditions. Periapical fluid could be especially helpful to monitor early signs of healing in a two-visit treatment approach $(114,116,117)$. In contrast to the slow recession of periapical radiolucencies, the change in molecular composition of periapical fluid appears to occur quickly, and thus a chair-side assay could be helpful to decide at the beginning of the second endodontic visit whether a root canal system can be filled or requires more thorough disinfection.

\section{Which target molecules should be considered?}

Pulpitis and apical periodontitis are caused by mixed opportunistic infections. The host response to these is collectively termed the innate or non-specific immune system. Histologic studies clearly show that pulpitis is a PMN-driven inflammation $(15,118)$. In fact, the PMNs form a wall of defense against the microbial invaders (26). PMNs produce a whole array of proteolytic enzymes $(119,120)$. These digest soft tissue and make it possible for the PMNs to infiltrate the site of bacterial invasion. However, the innate defense mechanism has also its limits. If the microbial invaders are not removed from the tooth, abscess formation ensues (121), and the pulp tissue necrotizes. In the context of disease progression, this means that the host gradually loses its access to the site of microbial presence (Fig. 3). In the periapical tissues the situation is slightly more complex, because bone resorption occurs concomitantly to the recruitment of the 
inflammatory infiltrate (107). Nevertheless, the basics of the immune response remain similar in the pulp space and the periapical area.

Studies on whole pulp tissue consistently showed that PMN-related enzymes such as Elastase and Cathepsin G $(122,123)$ and MMP-9 (124) are elevated in clinically inflamed compared to healthy dental pulps. Histologically, the presence of these enzymes or their respective mRNAs is strongly correlated to the inflammatory infiltrate $(125,126)$. The same is true for IL-8, the main neutrophil chemoattractant. At the gene expression level, IL-8 levels are distinctly different between clinically healthy and inflamed human dental pulps, while upstream genes encoding for early inflammatory responses such as IL-1 $\beta$ do not differ between these clinical states (127). IL-8 expression is also spatially correlated with the inflammatory infiltrate (128).

When it comes to monitoring periapical health, the picture is less clear (107). This is probably also because some studies aiming to identify factors associated with apical periodontitis investigated chronic lesions undergoing apical surgery rather than progressive (acute) lesions (129). These lesions could effectively represent relatively healthy tissue with little propensity to ever become acute (130).

Based on these biological givens, it makes most sense to monitor PMN-related factors in molecular diagnostics. Less site-specific, upstream inflammatory markers such as IL-1 $\beta$ are not suitable as markers for pulpitis $(90,127)$, and probably also not for apical periodontitis. Most interestingly, all the studies that have been performed thus far comparing clinically healthy and diseased teeth by assessing PMN-related markers in GCF, pulpal blood, dentinal fluid, or periapical fluid, a significant difference was found between the two states (Table 1). PMN factors could thus also be key in identifying an on-going inflammatory process in the periapex. A recent study by the authors showed the absence of IL-8 at the protein level in periapical fluid of teeth with irreversible pulpitis, in contrast to counterparts with apical periodontitis (131). Alternatively, 
factors associated with bone resorption could be targeted, but these appear to provide less unequivocal results (132).

As clinicians, perhaps unknowingly, we already take PMN activity into account when treating teeth with apical periodontitis and a fistula. If the fistula disappears after the first visit, we know that healing has initiated. If the fistula is still there at the second visit, we know that we have to improve our root canal disinfection protocol and/or consider the (rare!) possibility of a selfsustaining extra-radicular infection (133).

\section{Chairside assays: will they ever be possible?}

In dentistry, few sophisticated diagnostic tests have ever made it to market. The main reason for this is probably that cost and time for these assays do not justify their application. Nevertheless, it is interesting to note that in periodontology, molecular testing methods have found their way into clinics (134), even though potential overtreatment by the dental hygienist is cheaper than most of the tests that are currently on the market, with little or no side effects for the patient. In endodontology, all the procedures are usually performed by a specialized dentist, and are therefore expensive. Furthermore, false treatment decisions may cause severe pain to the patient. Consequently, it would make sense to develop better diagnostic tests not only from a health perspective, but also from a socio-economic point of view. Ideally, these tests should be performed chair-side, because it makes little sense to recall a patient just because we have to wait for a test result from the lab.

The levels of host factors discussed in this communication can, in theory, be assessed at three levels: gene expression (mRNA), protein, and active protein. Assays targeting the gene expression level are unlikely to ever be applicable in a chair-side set-up. The one GCF assay that is on the market to measure soft tissue breakdown in periodontal pockets targets active MMP-8, 
and thus, PMN activity $(135,136)$. This assay is based on the immunochromatography principle, which uses two monoclonal antibodies specific for different epitopes of MMP-8. The assay is essentially similar to a common pregnancy test, just with a different target molecule. It has been sold under various brand names such as PerioSafe and Periomarker by different companies, such as Dentognostics, Hager und Werken $\mathrm{GmbH}$, and GlaxoSmithKline Consumer Healthcare. The priority date for the underlying patent (WO1996007103 A1), filed by Professor Timo Sorsa, was August 26, 1994. The patent will thus expire this year. It would be most interesting to evaluate whether such assays could also be developed for the analysis of dentinal and periapical fluid. With the former, there will most likely be a sensitivity problem, as the target proteins collected from dentinal fluid are in the low ng range (101). With periapical fluid, on the other hand, yields are similar to GCF, and assays could be developed easily.

\section{Concluding remarks}

In summary, we can state that much research is necessary to advance molecular diagnostics in endodontology. However, it would appear that it is worth the effort. This communication was composed to summarize information, which is not normally presented in this clinical context. Apparently, few researchers have embraced this topic, and hopefully, this will change in the near future. Based on the current state of knowledge, some key points should be investigated:

- Detection of bacterial aggregates in the root canal/ dental pulp by direct optical methods;

- improvement of protein yield in dentinal fluid collection;

- interference of pulpal blood with the assessment of target proteins;

- correlation between PMN markers in dentinal and/or periapical fluid and clinical outcomes, such as maintained pulp vitality or healing of periapical lesions. 


\section{Acknowledgement}

The authors want to thank Prof. George Belibasakis and Dr. Nagihan Bostanci, both from the Institute of Oral Biology, University of Zürich, for their help with this text. 


\section{Captions}

Figure 1. Schematic depiction of different histiological states of the pulp and the periapex, which can be encountered with similar results obtained by current diagnostic tests. Bacterial invasion is represented in green, inflammatory infiltrate in red. With a positive pulp test, in the absence of radiolucency, the pulp may already be infected and thus irreversibly inflamed, at least in its coronal aspect (top right). With a negative pulp test and an apical radiolucency, on the other hand, parts of the pulp tissue may still be vital and not necessarily be infiltrated with inflammatory cells (bottom, left). This diagram should highlight the need for better, site-specific diagnostics that can reveal the state of the pulp and/or the periapex.

Figure 2. Longitudinal section of a molar affected by caries excited with violet light (370-420 $\mathrm{nm}$ ) and observed through a $530 \mathrm{~nm}$ highpass filter (A). This method is applied clinically in a system known as FACE (fluorescence-aided caries excavation). A clinical picture (B) shows a premolar before complete caries excavation. The method highlights porphyrin rings, which are abundant in the presence of certain bacteria. This can be appreciated by directly monitoring bacterial colonies: Prevotella intermedia growing on blood agar depicted using the FACE method (C). These images are courtesy of Prof. Wolfgang Buchalla, Regensburg, Germany.

Figure 3. Microscopic view of a histologic specimen from a mandibular molar affected by caries. Note the heavy infiltration of the pulp tissue with polymorphonuclear neutrophil granulocytes (PMNs), leading to abscess formation and pulp necrosis (courtesy of Prof. emeritus Hans-Ueli Luder, University of Zürich). 


\section{References}

1. Kakehashi S, Stanley HR, Fitzgerald RJ. The effects of surgical exposures of dental pulps in germ-free and conventional laboratory rats. Oral Surg Oral Med Oral Pathol 1965: 20: 340-349.

2. Bergenholtz G. Micro-organisms from necrotic pulp of traumatized teeth. Odontol Revy 1974: 25: 347-358.

3. Warfvinge J, Bergenholtz G. Healing capacity of human and monkey dental pulps following experimentally-induced pulpitis. Endod Dent Traumatol 1986: 2: 256-262.

4. Sjogren U, Figdor D, Persson S, Sundqvist G. Influence of infection at the time of root filling on the outcome of endodontic treatment of teeth with apical periodontitis. Int Endod J 1997: 30: 297-306.

5. Mejare IA, Axelsson S, Davidson T, Frisk F, Hakeberg M, Kvist T, Norlund A, Petersson A, Portenier I, Sandberg H, Tranaeus S, Bergenholtz G. Diagnosis of the condition of the dental pulp: a systematic review. Int Endod J 2012: 45: 597-613.

6. Levin LG. Pulp and periradicular testing. J Endod 2013: 39: S13-9.

7. Chen E, Abbott PV. Dental pulp testing: a review. Int J Dent 2009: 2009: 365785.

8. Olgart L, Gazelius B, Lindh-Stromberg U. Laser Doppler flowmetry in assessing vitality in luxated permanent teeth. Int Endod J 1988: 21: 300-306.

9. Schmitt JM, Webber RL, Walker EC. Optical determination of dental pulp vitality. IEEE Trans Biomed Eng 1991: 38: 346-352.

10. Nissan R, Trope M, Zhang CD, Chance B. Dual wavelength spectrophotometry as a diagnostic test of the pulp chamber contents. Oral Surg Oral Med Oral Pathol 1992: 74: 508-514. 
11. Dummer PM, Hicks R, Huws D. Clinical signs and symptoms in pulp disease. Int Endod J 1980: 13: 27-35.

12. Michaelson PL, Holland GR. Is pulpitis painful? Int Endod J 2002: 35: 829-832.

13. Rowe AH, Pitt Ford TR. The assessment of pulpal vitality. Int Endod J 1990: 23: 77-83.

14. Brynolf I. A histological and roentgenological study of the periapical region of human upper incisors. 1967:

15. Langeland K. Tissue response to dental caries. Endod Dent Traumatol 1987: 3: 149-171.

16. Orstavik D. Time-course and risk analyses of the development and healing of chronic apical periodontitis in man. Int Endod $J$ 1996: 29: 150-155.

17. Bender IB, Seltzer S. Roentgenographic and direct observation of experimental lesions in bone: I. 1961. J Endod 2003: 29: 702-6; discussion 701.

18. Bender IB, Seltzer S. Roentgenographic and direct observation of experimental lesions in bone: II. 1961. J Endod 2003: 29: 707-12; discussion 701.

19. Patel S. New dimensions in endodontic imaging: Part 2. Cone beam computed tomography. Int Endod J 2009: 42: 463-475.

20. Pauwels R, Beinsberger J, Collaert B, Theodorakou C, Rogers J, Walker A, Cockmartin L, Bosmans H, Jacobs R, Bogaerts R, Horner K. Effective dose range for dental cone beam computed tomography scanners. Eur J Radiol 2012: 81: 267-271.

21. Barthel CR, Zimmer S, Trope M. Relationship of radiologic and histologic signs of inflammation in human root-filled teeth. J Endod 2004: 30: 75-79.

22. Rud J, Andreasen JO, Jensen JE. Radiographic criteria for the assessment of healing after endodontic surgery. Int J Oral Surg 1972: 1: 195-214. 
23. Pope O, Sathorn C, Parashos P. A Comparative Investigation of Cone-beam Computed Tomography and Periapical Radiography in the Diagnosis of a Healthy Periapex. $J$ Endod 2014: 40: 360-365.

24. Cameron CE. Cracked-tooth syndrome. J Am Dent Assoc 1964: 68: 405-411.

25. Nagaoka S, Miyazaki Y, Liu HJ, Iwamoto Y, Kitano M, Kawagoe M. Bacterial invasion into dentinal tubules of human vital and nonvital teeth. J Endod 1995: 21: 70-73.

26. Nair PNR. Apical periodontitis: a dynamic encounter between root canal infection and host response. Periodontol 2000 1997: 13: 121-148.

27. Ricucci D, Siqueira JFJ. Biofilms and apical periodontitis: study of prevalence and association with clinical and histopathologic findings. J Endod 2010: 36: 1277-1288.

28. Ricucci D, Loghin S, Siqueira JFJ. Exuberant Biofilm infection in a lateral canal as the cause of short-term endodontic treatment failure: report of a case. J Endod 2013: 39: 712718.

29. Arnold M, Ricucci D, Siqueira JFJ. Infection in a complex network of apical ramifications as the cause of persistent apical periodontitis: a case report. J Endod 2013: 39: 1179-1184.

30. Friedman S, Mor C. The success of endodontic therapy--healing and functionality. J Calif Dent Assoc 2004: 32: 493-503.

31. Ng YL, Mann V, Rahbaran S, Lewsey J, Gulabivala K. Outcome of primary root canal treatment: systematic review of the literature -- Part 2. Influence of clinical factors. Int Endod J 2008: 41: 6-31.

32. Gold SI. Paeeriodontics. The past. Microbiology. Part (III). J Clin Periodontol 1985: 12: 257-269.

33. Pellegrino ED, Pellegrino AA. Humanism and ethics in Roman medicine: translation and commentary on a text of Scribonius Largus. Lit Med 1988: 7: 22-38. 
34. Barthel CR, Rosenkranz B, Leuenberg A, Roulet JF. Pulp capping of carious exposures: treatment outcome after 5 and 10 years: a retrospective study. $J$ Endod 2000: 26: 525-528.

35. Brynjulfsen A, Fristad I, Grevstad T, Hals-Kvinnsland I. Incompletely fractured teeth associated with diffuse longstanding orofacial pain: diagnosis and treatment outcome. Int Endod J 2002: 35: 461-466.

36. Mertz-Fairhurst EJ, Curtis JWJ, Ergle JW, Rueggeberg FA, Adair SM. Ultraconservative and cariostatic sealed restorations: results at year 10. J Am Dent Assoc 1998: 129: 55-66.

37. Fitzgerald M, Heys RJ. A clinical and histological evaluation of conservative pulpal therapy in human teeth. Oper Dent 1991: 16: 101-112.

38. Leksell E, Ridell K, Cvek M, Mejare I. Pulp exposure after stepwise versus direct complete excavation of deep carious lesions in young posterior permanent teeth. Endod Dent Traumatol 1996: 12: 192-196.

39. Bjorndal L, Reit C, Bruun G, Markvart M, Kjaeldgaard M, Nasman P, Thordrup M, Dige I, Nyvad B, Fransson H, Lager A, Ericson D, Petersson K, Olsson J, Santimano EM, Wennstrom A, Winkel P, Gluud C. Treatment of deep caries lesions in adults: randomized clinical trials comparing stepwise vs. direct complete excavation, and direct pulp capping vs. partial pulpotomy. Eur J Oral Sci 2010: 118: 290-297.

40. Jokstad A. After 10 years seven out of ten fixed dental prostheses (FDP) remain intact and nine out of ten FDPs remain in function following biological and technical complications that have been repaired. J Evid Based Dent Pract 2010: 10: 39-40.

41. Cheung GS, Lai SC, Ng RP. Fate of vital pulps beneath a metal-ceramic crown or a bridge retainer. Int Endod J 2005: 38: 521-530.

42. Bergenholtz G, Nyman S. Endodontic complications following periodontal and prosthetic treatment of patients with advanced periodontal disease. J Periodontol 1984: 55: 63-68. 
43. Schilder H, Goodman A, Aldrich W. The thermomechanical properties of gutta-percha. 3 . Determination of phase transition temperatures for gutta-percha. Oral Surg Oral Med Oral Pathol 1974: 38: 109-114.

44. Bender IB, Seltzer S, Turkenkopf S. To culture or not to culture? Oral Surg Oral Med Oral Pathol 1964: 18: 527-540.

45. Tronstad L. Tissue reactions following apical plugging of the root canal with dentin chips in monkey teeth subjected to pulpectomy. Oral Surg Oral Med Oral Pathol 1978: 45: 297304.

46. Oswald RJ, Friedman CE. Periapical response to dentin filings. A pilot study. Oral Surg Oral Med Oral Pathol 1980: 49: 344-355.

47. Wu MK, Wesselink PR, Walton RE. Apical terminus location of root canal treatment procedures. Oral Surg Oral Med Oral Pathol Oral Radiol Endod 2000: 89: 99-103.

48. Simon S, Perard M, Zanini M, Smith AJ, Charpentier E, Djole SX, Lumley PJ. Should pulp chamber pulpotomy be seen as a permanent treatment? Some preliminary thoughts. Int Endod J 2013: 46: 79-87.

49. Asgary S, Eghbal MJ. The effect of pulpotomy using a calcium-enriched mixture cement versus one-visit root canal therapy on postoperative pain relief in irreversible pulpitis: a randomized clinical trial. Odontology 2010: 98: 126-133.

50. Asgary S, Eghbal MJ. Treatment outcomes of pulpotomy in permanent molars with irreversible pulpitis using biomaterials: a multi-center randomized controlled trial. Acta Odontol Scand 2013: 71: 130-136.

51. Murray PE, Garcia-Godoy F, Hargreaves KM. Regenerative endodontics: a review of current status and a call for action. J Endod 2007: 33: 377-390. 
52. Hargreaves KM, Giesler T, Henry M, Wang Y. Regeneration potential of the young permanent tooth: what does the future hold? J Endod 2008: 34: S51-6.

53. Andreasen JO. Pulp and periodontal tissue repair - regeneration or tissue metaplasia after dental trauma. A review. Dent Traumatol 2012: 28: 19-24.

54. Nygaard-Ostby B. The role of the blood clot in endodontic therapy. An experimenal histologic study. Acta Odontol Scand 1961: 19: 323-353.

55. Nygaard-Ostby B, Hjortdal O. Tissue formation in the root canal following pulp removal. Scand J Dent Res 1971: 79: 333-349.

56. Iwaya SI, Ikawa M, Kubota M. Revascularization of an immature permanent tooth with apical periodontitis and sinus tract. Dent Traumatol 2001: 17: 185-187.

57. Trope M. Treatment of the immature tooth with a non-vital pulp and apical periodontitis. Dent Clin North Am 2010: 54: 313-324.

58. Becerra P, Ricucci D, Loghin S, Gibbs JL, Lin LM. Histologic study of a human immature permanent premolar with chronic apical abscess after revascularization/revitalization. $J$ Endod 2014: 40: 133-139.

59. Mao JJ, Kim SG, Zhou J, Ye L, Cho S, Suzuki T, Fu SY, Yang R, Zhou X. Regenerative endodontics: barriers and strategies for clinical translation. Dent Clin North Am 2012: 56: 639-649.

60. Lane AJ, Grossman LI. Culturing root canals by endodontic diplomates: a report based on a questionnaire. Oral Surg Oral Med Oral Pathol 1971: 32: 461-466.

61. Sundqvist G. Taxonomy, ecology, and pathogenicity of the root canal flora. Oral Surg Oral Med Oral Pathol 1994: 78: 522-530.

62. Marsh PD. Sugar, fluoride, $\mathrm{pH}$ and microbial homeostasis in dental plaque. Proc Finn Dent Soc 1991: 87: 515-525. 
63. Chavez de Paz LE. Redefining the persistent infection in root canals: possible role of biofilm communities. J Endod 2007: 33: 652-662.

64. Walton RE. Culturing the exudate of an odontogenic infection--a useful procedure? Oral Surg Oral Med Oral Pathol Oral Radiol Endod 1999: 88: 525.

65. Moller AJR. Microbiological examination of root canals and periapical tissues of human teeth. Methodological studies. Odontol Tidskr 1966: 74: Suppl:1-380.

66. Ng YL, Spratt D, Sriskantharajah S, Gulabivala K. Evaluation of protocols for field decontamination before bacterial sampling of root canals for contemporary microbiology techniques. J Endod 2003: 29: 317-320.

67. Lennon AM, Buchalla W, Brune L, Zimmermann O, Gross U, Attin T. The ability of selected oral microorganisms to emit red fluorescence. Caries Res 2006: 40: 2-5.

68. Lennon AM, Buchalla W, Switalski L, Stookey GK. Residual caries detection using visible fluorescence. Caries Res 2002: 36: 315-319.

69. Buchalla W, Lennon AM, Attin T. Comparative fluorescence spectroscopy of root caries lesions. Eur J Oral Sci 2004: 112: 490-496.

70. Prader F. Das lokale Blutbild bei pulpitischer Ersteröffnung. Schweiz Monatsschr Zahnmed 1949: 50: 6-11.

71. Curtis MA, Sterne JA, Price SJ, Griffiths GS, Coulthurst SK, Wilton JM, Johnson NW. The protein composition of gingival crevicular fluid sampled from male adolescents with no destructive periodontitis: baseline data of a longitudinal study. J Periodontal Res 1990: 25: 6-16.

72. Kuo ML, Lamster IB, Hasselgren G. Host mediators in endodontic exudates. I. Indicators of inflammation and humoral immunity. J Endod 1998: 24: 598-603. 
73. Taba MJ, Kinney J, Kim AS, Giannobile WV. Diagnostic biomarkers for oral and periodontal diseases. Dent Clin North Am 2005: 49: 551-71, vi.

74. Lamster IB. Evaluation of components of gingival crevicular fluid as diagnostic tests. Ann Periodontol 1997: 2: 123-137.

75. Loos BG, Tjoa S. Host-derived diagnostic markers for periodontitis: do they exist in gingival crevice fluid? Periodontol 2000 2005: 39: 53-72.

76. George A, Evans CA. Detection of root resorption using dentin and bone markers. Orthod Craniofac Res 2009: 12: 229-235.

77. Kumar V, Logani A, Shah N. Dentine sialoprotein expression in gingival crevicular fluid during trauma-induced root resorption. Int Endod J 2013: 46: 371-378.

78. Vertucci FJ, Williams RG. Furcation canals in the human mandibular first molar. Oral Surg Oral Med Oral Pathol 1974: 38: 308-314.

79. Capra NF, Anderson KV, Pride JB, Jones TE. Simultaneous demonstration of neuronal somata that innervate the tooth pulp and adjacent periodontal tissues, using two retrogradely transported anatomic markers. Exp Neurol 1984: 86: 165-170.

80. Awawdeh LA, Lundy FT, Linden GJ, Shaw C, Kennedy JG, Lamey PJ. Quantitative analysis of substance $\mathrm{P}$, neurokinin $\mathrm{A}$ and calcitonin gene-related peptide in gingival crevicular fluid associated with painful human teeth. Eur J Oral Sci 2002: 110: 185-191.

81. Avellan NL, Sorsa T, Tervahartiala T, Forster C, Kemppainen P. Experimental tooth pain elevates substance $\mathrm{P}$ and matrix metalloproteinase- 8 levels in human gingival crevice fluid. Acta Odontol Scand 2008: 66: 18-22.

82. Karapanou V, Kempuraj D, Theoharides TC. Interleukin-8 is increased in gingival crevicular fluid from patients with acute pulpitis. J Endod 2008: 34: 148-151. 
83. Shin SJ, Lee W, Lee JI, Baek SH, Kum KY, Shon WJ, Bae KS. Matrix metalloproteinase-8 and substance $\mathrm{P}$ levels in gingival crevicular fluid during endodontic treatment of painful, nonvital teeth. Oral Surg Oral Med Oral Pathol Oral Radiol Endod 2011: 112: 548-554.

84. Belmar MJ, Pabst C, Martinez B, Hernandez M. Gelatinolytic activity in gingival crevicular fluid from teeth with periapical lesions. Oral Surg Oral Med Oral Pathol Oral Radiol Endod 2008: 105: 801-806.

85. Dezerega A, Madrid S, Mundi V, Valenzuela MA, Garrido M, Paredes R, Garcia-Sesnich J, Ortega AV, Gamonal J, Hernandez M. Pro-oxidant status and matrix metalloproteinases in apical lesions and gingival crevicular fluid as potential biomarkers for asymptomatic apical periodontitis and endodontic treatment response. J Inflamm (Lond) 2012: 9: 8.

86. Burgener B, Ford AR, Situ H, Fayad MI, Hao JJ, Wenckus CS, Johnson BR, BeGole EA, George A. Biologic markers for odontogenic periradicular periodontitis. J Endod 2010: 36: 1307-1310.

87. Hahn CL, Liewehr FR. Relationships between caries bacteria, host responses, and clinical signs and symptoms of pulpitis. J Endod 2007: 33: 213-219.

88. Lovelace TW, Henry MA, Hargreaves KM, Diogenes A. Evaluation of the delivery of mesenchymal stem cells into the root canal space of necrotic immature teeth after clinical regenerative endodontic procedure. J Endod 2011: 37: 133-138.

89. Guthrie TJ, McDonald RE, Mitchell DF. Dental pulp hemogram. J Dent Res 1965: 44: 678682.

90. Nakanishi T, Matsuo T, Ebisu S. Quantitative analysis of immunoglobulins and inflammatory factors in human pulpal blood from exposed pulps. J Endod 1995: 21: 131136. 
91. Elsalhy M, Azizieh F, Raghupathy R. Cytokines as diagnostic markers of pulpal inflammation. Int Endod J 2013: 46: 573-580.

92. Brown RE, Jarvis KL, Hyland KJ. Protein measurement using bicinchoninic acid: elimination of interfering substances. Anal Biochem 1989: 180: 136-139.

93. Grebenchtchikov N, Sweep CG, Geurts-Moespot A, Piffanelli A, Foekens JA, Benraad TJ. An ELISA avoiding interference by heterophilic antibodies in the measurement of components of the plasminogen activation system in blood. J Immunol Methods 2002: 268: 219-231.

94. Coffey CT, Ingram MJ, Bjorndal AM. Analysis of human dentinal fluid. Oral Surg Oral Med Oral Pathol 1970: 30: 835-837.

95. Maita E, Simpson MD, Tao L, Pashley DH. Fluid and protein flux across the pulpodentine complex of the dog in vivo. Arch Oral Biol 1991: 36: 103-110.

96. Knutsson G, Jontell M, Bergenholtz G. Determination of plasma proteins in dentinal fluid from cavities prepared in healthy young human teeth. Arch Oral Biol 1994: 39: 185-190.

97. Geraldeli S, Li Y, Hogan MM, Tjaderhane LS, Pashley DH, Morgan TA, Zimmerman MB, Brogden KA. Inflammatory mediators in fluid extracted from the coronal occlusal dentine of trimmed teeth. Arch Oral Biol 2012: 57: 264-270.

98. Sulkala M, Larmas M, Sorsa T, Salo T, Tjaderhane L. The localization of matrix metalloproteinase-20 (MMP-20, enamelysin) in mature human teeth. J Dent Res 2002: 81: 603-607.

99. Zehnder M, Wegehaupt FJ, Attin T. A first study on the usefulness of matrix metalloproteinase 9 from dentinal fluid to indicate pulp inflammation. J Endod 2011: 37: $17-20$. 
100. Johnson RB, Streckfus CF, Dai X, Tucci MA. Protein recovery from several paper types used to collect gingival crevicular fluid. J Periodontal Res 1999: 34: 283-289.

101. Zehnder M, Rechenberg DK, Bostanci N, Sizman F, Attin T. Comparison of vehicles to collect dentinal fluid for molecular analyisis. J Dent 2014: in press:

102. Matsuo T, Ebisu S, Nakanishi T, Yonemura K, Harada Y, Okada H. Interleukin-1 alpha and interleukin-1 beta periapical exudates of infected root canals: correlations with the clinical findings of the involved teeth. J Endod 1994: 20: 432-435.

103. Shimauchi H, Takayama S, Miki Y, Okada H. The change of periapical exudate prostaglandin E2 levels during root canal treatment. J Endod 1997: 23: 755-758.

104. Matsuo T, Nakanishi T, Ebisu S. Immunoglobulins in periapical exudates of infected root canals: correlations with the clinical findings of the involved teeth. Endod Dent Traumatol 1995: 11: 95-99.

105. Baugh D, Wallace J. The role of apical instrumentation in root canal treatment: a review of the literature. J Endod 2005: 31: 333-340.

106. Henriques LC, de Brito LC, Tavares WL, Vieira LQ, Ribeiro Sobrinho AP. Cytokine analysis in lesions refractory to endodontic treatment. J Endod 2011: 37: 1659-1662.

107. Stashenko P, Teles R, D'Souza R. Periapical inflammatory responses and their modulation. Crit Rev Oral Biol Med 1998: 9: 498-521.

108. Horiba N, Maekawa Y, Abe Y, Ito M, Matsumoto T, Nakamura H. Correlations between endotoxin and clinical symptoms or radiolucent areas in infected root canals. Oral Surg Oral Med Oral Pathol 1991: 71: 492-495.

109. Safavi KE, Rossomando EF. Tumor necrosis factor identified in periapical tissue exudates of teeth with apical periodontitis. J Endod 1991: 17: 12-14. 
110. Wahlgren J, Salo T, Teronen O, Luoto H, Sorsa T, Tjaderhane L. Matrix metalloproteinase8 (MMP-8) in pulpal and periapical inflammation and periapical root-canal exudates. Int Endod J 2002: 35: 897-904.

111. Guo X, Niu Z, Xiao M, Yue L, Lu H. Detection of interleukin-8 in exudates from normal and inflamed human dental pulp tissues. Chin J Dent Res 2000: 3: 63-66.

112. Shimauchi H, Takayama S, Narikawa-Kiji M, Shimabukuro Y, Okada H. Production of interleukin-8 and nitric oxide in human periapical lesions. J Endod 2001: 27: 749-752.

113. Alptekin NO, Ari H, Ataoglu T, Haliloglu S, Alptekin T, Serpek B. Neutrophil elastase levels in periapical exudates of symptomatic and asymptomatic teeth. $J$ Endod 2005: 31: $350-353$.

114. Alptekin NO, Ari H, Haliloglu S, Alptekin T, Serpek B, Ataoglu T. The effect of endodontic therapy on periapical exudate neutrophil elastase and prostaglandin-E2 levels. $J$ Endod 2005: 31: 791-795.

115. Takayama S, Miki Y, Shimauchi H, Okada H. Relationship between prostaglandin E2 concentrations in periapical exudates from root canals and clinical findings of periapical periodontitis. J Endod 1996: 22: 677-680.

116. Tavares WL, de Brito LC, Henriques LC, Teles FR, Teles RP, Vieira LQ, Ribeiro Sobrinho AP. Effects of calcium hydroxide on cytokine expression in endodontic infections. $J$ Endod 2012: 38: 1368-1371.

117. Tavares WL, de Brito LC, Henriques LC, Oliveira RR, Maciel KF, Vieira LQ, Sobrinho AP. The impact of chlorhexidine-based endodontic treatment on periapical cytokine expression in teeth. $J$ Endod 2013: 39: 889-892.

118. Reeves R, Stanley HR. The relationship of bacterial penetration and pulpal pathosis in carious teeth. Oral Surg Oral Med Oral Pathol 1966: 22: 59-65. 
119. Janoff A. Elastase in tissue injury. Anпu Rev Med 1985: 36: 207-216.

120. Birkedal-Hansen H, Moore WG, Bodden MK, Windsor LJ, Birkedal-Hansen B, DeCarlo A, Engler JA. Matrix metalloproteinases: a review. Crit Rev Oral Biol Med 1993: 4: 197-250.

121. Sundqvist GK, Eckerbom MI, Larsson AP, Sjogren UT. Capacity of anaerobic bacteria from necrotic dental pulps to induce purulent infections. Infect Immun 1979: 25: 685-693.

122. Morand MA, Schilder H, Blondin J, Stone PJ, Franzblau C. Collagenolytic and elastinolytic activities from diseased human dental pulps. J Endod 1981: 7: 156-160.

123. Rauschenberger CR, McClanahan SB, Pederson ED, Turner DW, Kaminski EJ. Comparison of human polymorphonuclear neutrophil elastase, polymorphonuclear neutrophil cathepsin-G, and alpha 2-macroglobulin levels in healthy and inflamed dental pulps. J Endod 1994: 20: 546-550.

124. Gusman H, Santana RB, Zehnder M. Matrix metalloproteinase levels and gelatinolytic activity in clinically healthy and inflamed human dental pulps. Eur J Oral Sci 2002: 110: 353-357.

125. Cootauco CJ, Rauschenberger CR, Nauman RK. Immunocytochemical distribution of human PMN elastase and cathepsin-G in dental pulp. J Dent Res 1993: 72: 1485-1490.

126. Tsai $\mathrm{CH}$, Chen YJ, Huang FM, Su YF, Chang YC. The upregulation of matrix metalloproteinase-9 in inflamed human dental pulps. J Endod 2005: 31: 860-862.

127. Zehnder M, Delaleu N, Du Y, Bickel M. Cytokine gene expression--part of host defence in pulpitis. Cytokine 2003: 22: 84-88.

128. Huang GT, Potente AP, Kim JW, Chugal N, Zhang X. Increased interleukin-8 expression in inflamed human dental pulps. Oral Surg Oral Med Oral Pathol Oral Radiol Endod 1999: 88: $214-220$. 
129. Chan LT, Zhong S, Naqvi AR, Self-Fordham J, Nares S, Bair E, Khan AA. MicroRNAs: new insights into the pathogenesis of endodontic periapical disease. J Endod 2013: 39: 1498-1503.

130. Andreasen JO, Rud J. Correlation between histology and radiography in the assessment of healing after endodontic surgery. Int J Oral Surg 1972: 1: 161-173.

131. Rechenberg DK, Bostanci N, Zehnder M, Belibasakis GN. Periapical fluid RANKL and IL8 are differentially regulated in pulpitis and apical periodontitis. Cytokine 2014: submitted:

132. Belibasakis GN, Rechenberg DK, Zehnder M. The receptor activator of NF-kappaB ligandosteoprotegerin system in pulpal and periapical disease. Int Endod J 2013: 46: 99-111.

133. Sunde PT, Olsen I, Debelian GJ, Tronstad L. Microbiota of periapical lesions refractory to endodontic therapy. J Endod 2002: 28: 304-310.

134. Horz HP, Conrads G. Diagnosis and anti-infective therapy of periodontitis. Expert Rev Anti Infect Ther 2007: 5: 703-715.

135. Mantyla P, Stenman M, Kinane DF, Tikanoja S, Luoto H, Salo T, Sorsa T. Gingival crevicular fluid collagenase-2 (MMP-8) test stick for chair-side monitoring of periodontitis. J Periodontal Res 2003: 38: 436-439.

136. Sorsa T, Hernandez M, Leppilahti J, Munjal S, Netuschil L, Mantyla P. Detection of gingival crevicular fluid MMP-8 levels with different laboratory and chair-side methods. Oral Dis 2010: 16: 39-45. 

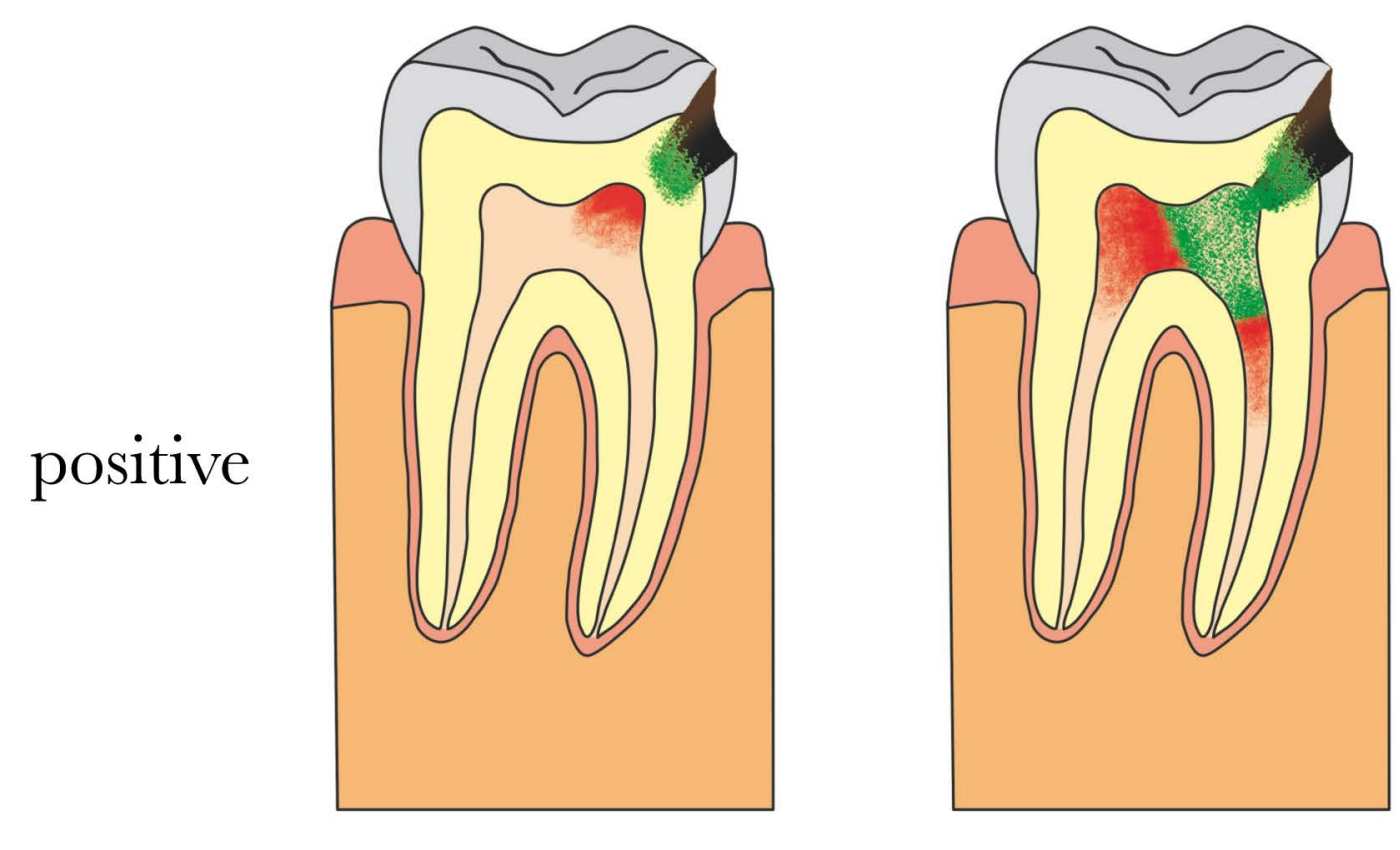

absent
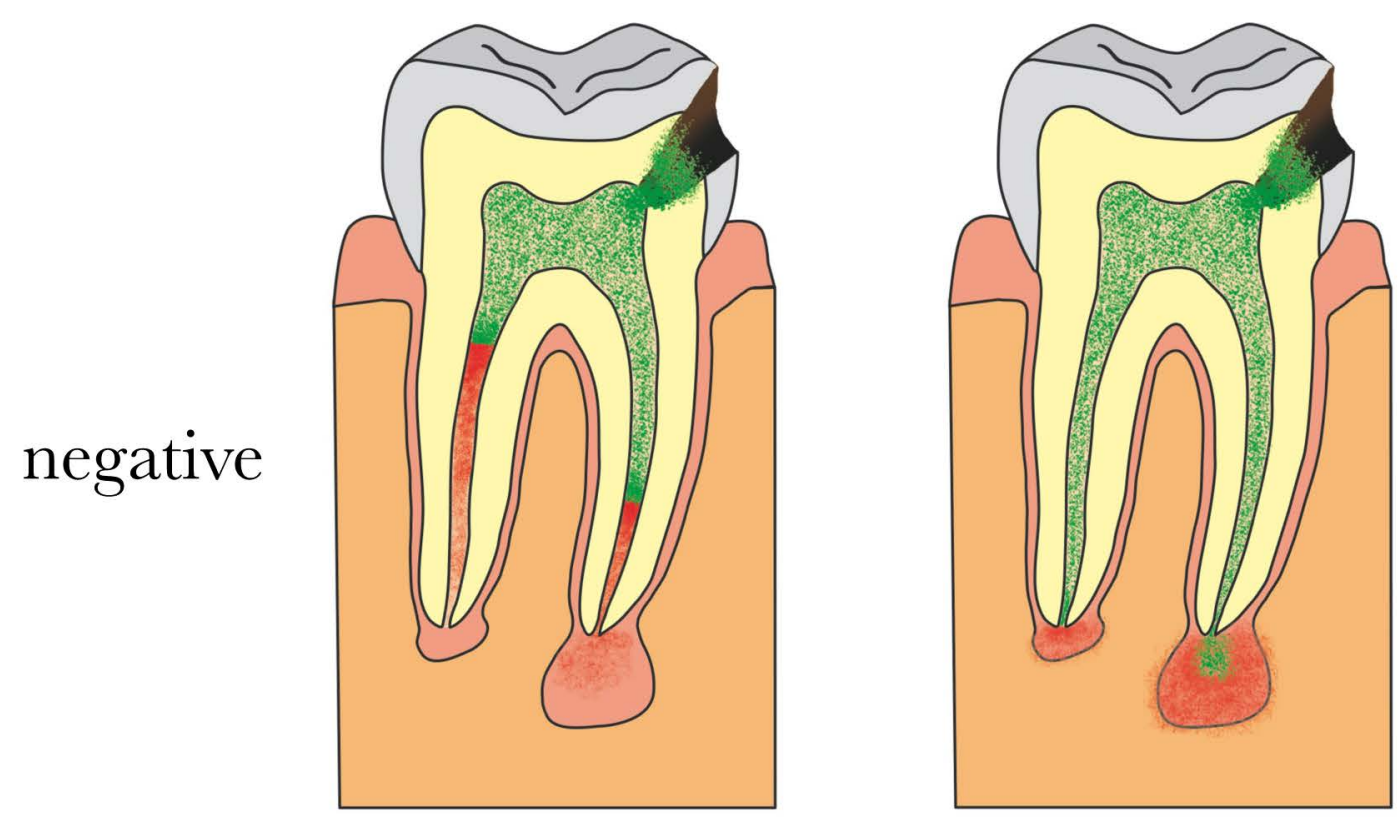

present 


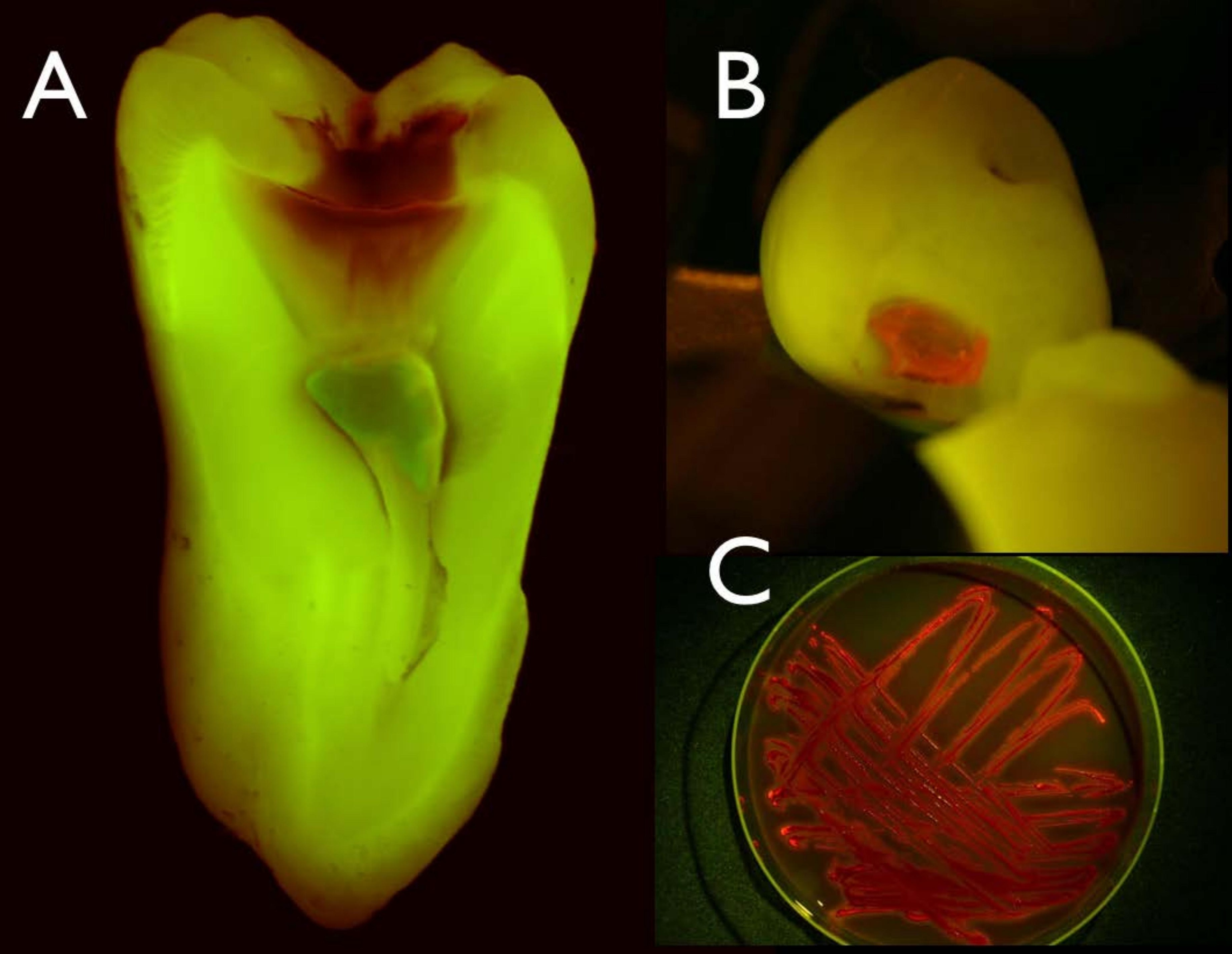




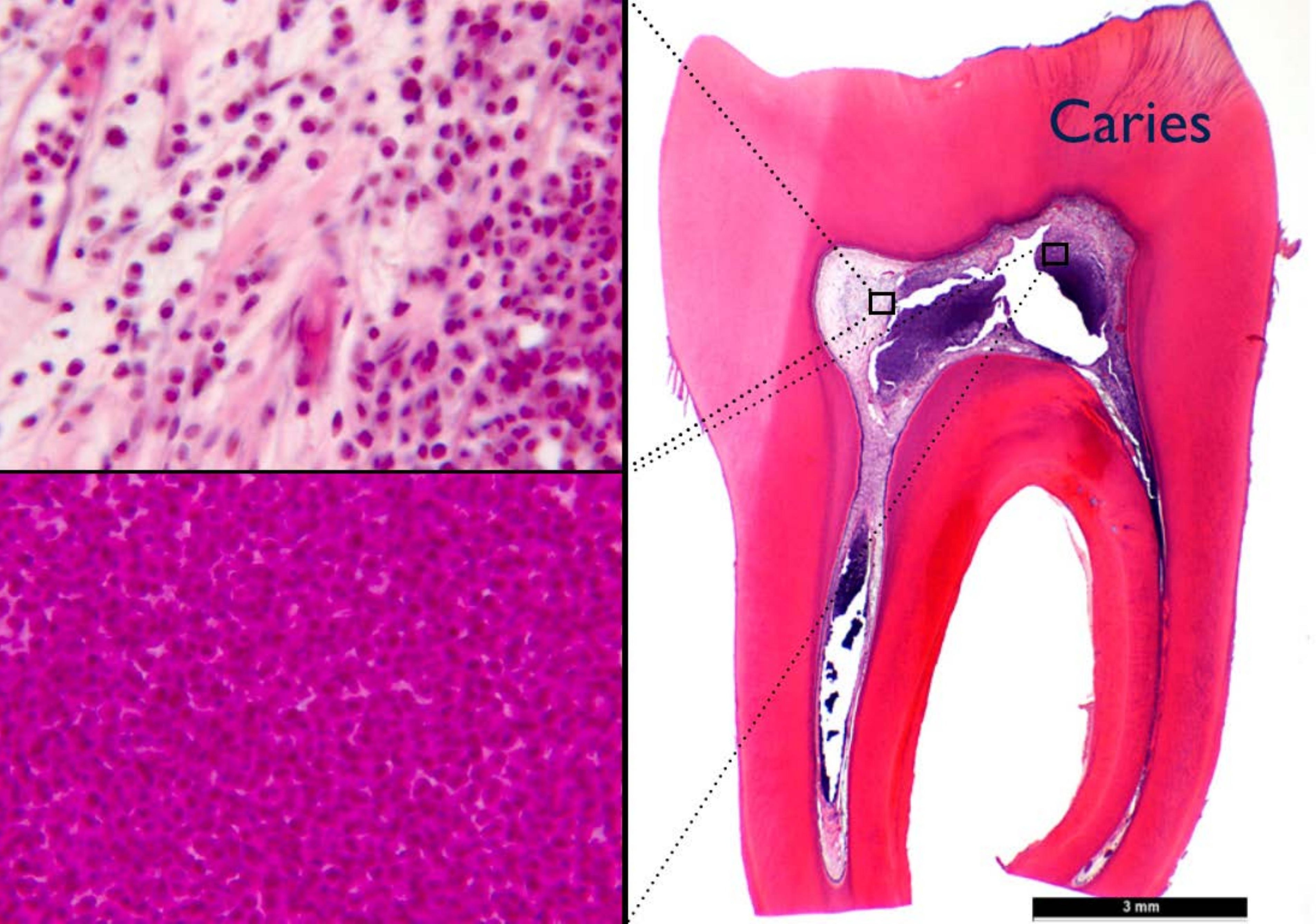


Table 1. Studies on PMN markers to diagnose the inflammatory status of the pulp or the periapex*

\begin{tabular}{|c|c|c|c|}
\hline Reference & Substrate & Target molecule(s) & Significant result** \\
\hline Karapanou et al. 2008 (82) & $\mathrm{GCF}$ & IL-8 & yes \\
\hline Shin et al. 2011 (83) & GCF & MMP-8 & yes \\
\hline Belmar et al. 2008 (84) & $\mathrm{GCF}$ & MMP-9 & yes \\
\hline Nakanishi et al. 1995 (90) & Pulpal blood & Elastase, prostaglandin E2 & yes \\
\hline Elsalhy et al. 2013 (91) & Pulpal blood & IL-8 & yes \\
\hline Zehnder et al. 2011 (99) & Dentinal fluid & MMP-9 & yes \\
\hline Wahlgren et al. 2002 (110) & Periapical fluid & MMP-8 & yes \\
\hline Guo et al. 2000 (111) & Periapical fluid & IL-8 & yes \\
\hline Shimauchi et al. 2001 (112) & Periapical fluid & IL-8 & yes \\
\hline Alptekin et al. 2005 (113) & Periapical fluid & Elastase & yes \\
\hline Alptekin et al. 2005 (114) & Periapical fluid & Elastase, prostaglandin E2 & yes \\
\hline
\end{tabular}

Numbers in parentheses relate to the numbers in the reference list.

Abbrevations: PMN: polymorphonuclear neutrophil granulocytes; GCF: gingival crevicular fluid.

*Only studies individual human teeth of different clinical states are included (no pooled samples).

**Significant difference at the $\leq 5 \%$ level between clinically/histologically healthy and diseased teeth. 